- Confidence intervals are appropriately in widespread use but were presented excessively in some articles

- P values are used more sparingly, but there is a tendency to overinterpret arbitrary cut offs such as $\mathrm{P}<0.05$

- The selection of and adjustment for potential confounders needs greater clarity, consistency, and explanation

- Subgroup analyses to identify effect modifiers mostly lack appropriate methods-for example, interaction tests-and are often overinterpreted

- Studies exploring many associations tend not to consider the increased risk of false positive findings

- The epidemiological literature seems prone to publication bias

- There are insufficient epidemiological publications in diseases other than cancer and cardiovascular diseases and in developing countries

- Overall, there is a serious risk that some epidemiological publications reach misleading conclusions.

We are grateful to Nicole Leong for her valuable contributions to getting the study underway. We thank Diana Elbourne, Stephen Evans, and John McKinlay for helpful comments on the draft manuscript.

Contributors: See bmj.com

Funding: None.

Competing interests: None declared.

Ethical approval: Not required.

1 Zeegers MPA, Volovics A, Dorant E, Goldbohm RA, van den Brant PA. Alcohol consumption and bladder cancer risk: results from the Netherlands cohort study. Am J Epidemiol 2001;153:38-41.

2 D'Agostino RB, Lee M-L, Belanger AJ, Cupples LA, Anderson K, Kannel WB. Relation of pooled logistic regression to time dependent Cox regression analysis: the Framingham heart study. Stat Med 1990;9:1501-15.

3 Rothman KJ. Writing for epidemiology. Epidemiology 1998;9:333-7.

4 Lang JM, Rothman KJ, Cann CI. That confounded P-value. Epidemiology 1998;9:7-8.

5 Weinberg CR. It's time to rehabilitate the P-value. Epidemiology 2001;12:288-90.
6 Lee KP, Schotland BA, Bacchetti P, Bero LA. Association of journal quality indicators with methodological quality of clinical research articles. JAMA 2002;287:2805-8.

7 Greenland S. Analysis of polytomous exposures and outcomes. In: Rothman KJ, Greenland S, eds. Modern epidemiology. Philadelphia: LippincottRaven, 1998:301-28.

8 Figueiras A, Cadarso-Suarez C. Application of nonparametric models for calculating odds ratios and their confidence intervals for continuous exposures. Am J Epidemiol 2001;154:264-75.

9 Zhao LP, Kolonel LN. Efficiency loss from categorizing quantitative exposures into qualitative exposures in case-control studies. Am J exposures into qualitative

10 Altman DG, Lausen B, Sauerbrei W, Schumacher W. Dangers of using "optimal" cutpoints in the evaluation of prognostic factors. J Nat Cancer Inst 1994;86:1798-9.

11 Davey-Smith G, Ebrahim, S. Data dredging, bias, or confounding. BMJ 2002;325:1437-8.

12 Clayton D, Hills M. Statistical models in epidemiology. Oxford: Oxford University Press, 1993

13 Goodman SN. Of P-values and Bayes: a modest proposal. Epidemiology 2001;12:295-7.

14 Sterne J, Davey-Smith, G. Sifting the evidence--what's wrong with significance tests? BMJ 2001;322:226-31.

15 Higginson J. Publication of "negative" epidemiology studies. J Chron Dis 1987;40:371-2.

16 Greenland S, Rothman K. Introduction to stratified analysis. In: Rothman K J, Greenland S, eds. Modern epidemiology. Philadelphia: LippincottRaven, 1998:253-80.

17 Greenland S. Modelling and variable selection in epidemiological analysis. Am J Pub Health 1989;79:340-9.

18 Assmann SF, Pocock SJ, Enos LE, Kasten LE. Subgroup analysis and other (mis)uses of baseline data in clinical trials. Lancet 2000;355:1064-9.

19 Yusuf S, Wittes J, Probstfield J, Tyroler HA. Analysis and interpretation of treatment effects in subgroups of patients in randomized clinical trials. JAMA 1991;266:93-8.

20 Ottenbacher KJ. Quantitative evaluation of multiplicity in epidemiology and public health research. Am J Epidemiol 1998;147:615-9.

21 Rushton L. Reporting of occupational and environmental research: use and misuse of statistical and epidemiological methods. Occup Environ Med 2000;57:1-9.

22 Phillips AN, Pocock SJ. Sample size requirements for prospective studies, with examples for coronary heart disease. J Clin Epidemiol 1989;42: 639-48.

23 Zhang Y, Felson DT, Curtis Ellison R, Kreger BE, Schatzkin A, Dorgan JF, et al. Bone mass and the risk of colon cancer among postmenopausal women. The Framingham study. Am J Epidemiol 2001;153:31-7.

24 Olson SH, Voigt LF, Begg CB, Weiss NS. Reporting participation in casecontrol studies. Epidemiology 2002;13:123-6.

(Accepted 7 September 2004)

doi $10.1136 /$ bmj.38250.571088.55

\title{
Mortality rates and self reported health: database analysis by English local authority area
}

\author{
Robert G E Kyffin, Michael J Goldacre, Mike Gill
}

Mortality rates are commonly used as summary measures of current health status when comparing different populations. Their use in this way is often criticised, however, because mortality rates, though readily available and objective, are such an extreme measure of ill health. Surveys of self reported health, as an alternative approach to quantifying the health of a population, tend to be regarded as flawed because of their subjectivity. The UK census in 2001 included two measures of self reported health. We compared their values for each local authority area with the mortality rates for each area to find out whether mortality and self reported health are correlated.

\section{Methods and results}

For each local authority area in England, we took the age standardised mortality rates for the major causes of death pooled for 1999 and 2001 from the Compendium of Clinical and Health Indicators.
For the same areas, we calculated age standardised rates of self reported health status using data from the 2001 census, ${ }^{2}$ using the European population as the standard. For the census question on general health everyone was asked whether, over the past 12 months, their "health had on the whole been good, fairly good, or not good." For the census question on limiting long term illness everyone was asked whether they had "any long term illness, health problem, or disability (including those due to old age)" which limited their daily activities or the work they could do. We plotted the rate for people in each local authority area who answered that their health had been "not good," and for those who answered "yes" to the question about long term

South East Regional Public Health Group, Government Office for the South East, Bridge House, Guildford, Surrey GU1 4GA Robert G E Kyffin public health intelligence officer Mike Gill regional director of public health continued over BMJ 2004;329:887-8 
Unit of Health-Care Epidemiology, Department of Public Health, University of Oxford, Institute of Health Sciences, Oxford OX3 7LF

Michael J Goldacre professor of public health

Correspondence to: R G E Kyffin robertkyffin@ dh.gsi.gov.uk illness, against the mortality rates for each area for all causes, cancer, circulatory disease, and suicide. To take account of differences in the numbers of deaths between the local authority areas, we used weighted least squares regression to derive Pearson correlation coefficients.

Area rates for "not good" health and for death from all causes were strongly correlated ( $\mathrm{R}=0.86$; figure), as were rates for limiting long term illness and death from all causes $(\mathrm{R}=0.84)$. We also found strong correlations between area rates for "not good" health and for cancer $(\mathrm{R}=0.79)$ and circulatory disease $(\mathrm{R}=0.77)$. The correlation with suicide was evident but not as strong $(\mathrm{R}=0.38)$. Rates of limiting long term illness and rates of death by specific causes showed similar patterns.

\section{Comment}

Mortality rates are highly correlated with the two census measures of self reported ill health at the level of local authority area. We cannot discount the possibility that, as measures of population health, mortality and self reported rates are both flawed in the same direction and to a similar extent. In other circumstances-for example, if comparing different cultures or for different time periods-the close relationship that we found may not hold.

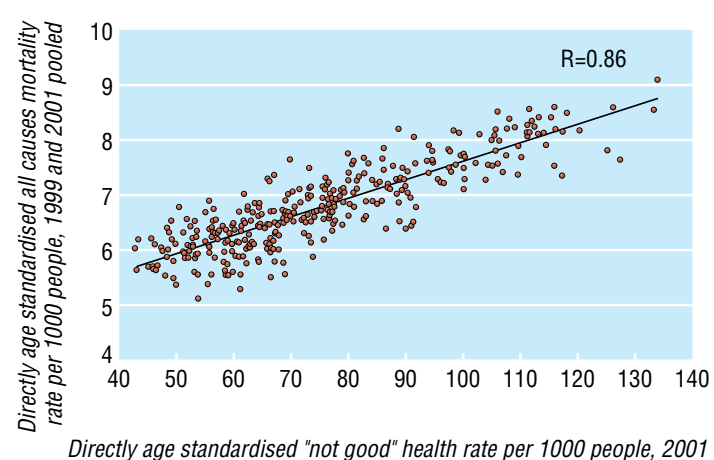

Relationship between age standardised rates of self reported "not good" health and all causes mortality rates at local authority level, England

\section{What is already known on this topic}

Mortality rates are commonly used as measures of population health, but this is often criticised as death is an extreme measure of ill health

Rates of self reported ill health also tend to be regarded as flawed because of their subjectivity

\section{What this study adds}

Comparing local authority areas in England, mortality rates are highly correlated with the two census measures of self reported ill health

We also noted the degree of scatter in the correlation: some local authorities with comparable mortality rates have quite different rates of self reported ill health and vice versa. If measures of either mortality or self reported ill health are used alone as weighting factors to determine allocation of resources to different areas, comparable levels of support could be received by areas with dissimilar need for services. In local authorities that have apparently large differences between their ranking on mortality and on self reported ill health, it may be worth exploring reasons for the difference.

For England as a whole, however, despite conceptual concerns about using either mortality or self reported ill health to measure the health status of different populations, there is a strong correlation between the two and each generally gives a similar profile.

Contributors: MJG proposed the study and wrote the first draft. RGEK analysed the data. All authors contributed to the design and interpretation of the study and to further drafts. RGEK is guarantor.

Funding: None.

Competing interests: None declared.

Ethical approval: Not needed.

1 Department of Health. Compendium of clinical and health indicators 2002. London: $\mathrm{DoH}, 2003$.

2 Office for National Statistics. 2001 census of population. London: ONS, 2003. www.statistics.gov.uk/census2001 (accessed 10 Sep 2004). (Accepted 28 July 2004)

doi 10.1136/bmj.38238.508021.F7

\section{One hundred years ago}

\section{The detection of early tubercle in the lungs}

In the year 1901, the last for which the Registrar-General's returns are available, there died in England and Wales 316,997 persons over the age of 20 , of whom 35,526 , or about one in every nine, were stated to owe their death to "phthisis" or "pulmonary tuberculosis." And these deaths are not deaths of old people, whose course was in any case nearly run. The victim of pulmonary tubercle is nearly always cut off in what should have been the most active period of his life, and usually after years of more or less complete disablement. Of this mass of suffering and premature death, repeating itself as it does year after year, much, perhaps the greater part, may be regarded as preventable, if proper treatment of the case be resorted to in time. But the condition of time is all important. Every month during which active tuberculous disease remains undetected and untreated lessens appreciably the prospect of recovery. I think, therefore, I am not exaggerating in saying that nothing in the art of medicine is of greater importance to acquire than the power of detecting with precision the early presence of this dangerous growth in the lung. For the means of doing so you have still chiefly to rely on the now old-fashioned means of physical examination. Bacteriology has supplemented, but cannot replace them. Even on the bare question of the presence or absence of tubercle in a lung it often fails us; on questions of the age, extent, distribution and histological character of the tuberculous lesions it can tell us little. The Roentgen ray is the latest addition to our implements of exploration. Though it is at present in its infancy it bids fair to render us valuable assistance; but, so far at least, we have little reason to think that it will ever rival the fingers and the ears for delicacy and exactitude of diagnosis.

(BMJ 1904;i:765) 